\title{
Editorial
}

\section{Issues in cardiac pacing: can agism be justified?}

Pacing the elderly is a controversial subject, with British Pacing and Electrophysiology Group (BPEG) guidelines ${ }^{1}$ emphasising the value of rate adaptive pacing (VVIR and DDD) for improved exercise tolerance and patient wellbeing. The view that ventricular demand pacing (VVI) pacing is "outmoded" has even been suggested" yet VVI continues to be used in over $70 \%$ of patients. The reality of clinical practice and important cost considerations must be faced (table). A recent report showed that adherence to BPEG recommendations would increase costs by $75 \%$ if optimum pacing systems were used and by $54 \%$ if alternative systems were used. ${ }^{3}$ The current costs per case for dual chamber pacing hardware is $£ 333$ a year (assuming a lifespan of 8 years and a cost per system of $£ 2666$ ) and though this is double the cost of VVI pacing it seems good value. The quality adjusted life year (QUALY) score for pacing is extremely favourable, ${ }^{4}$ giving clear support for the wider use of pacemaker treatment including rate adaptive systems for most patients. There is, however, reluctance to accept the BPEG guidelines particularly for the elderly. ${ }^{5-7}$ Is the extra cost of providing rate adaptive pacing for the elderly justified, bearing in mind competition for resources from other clinical areas and perhaps scrutiny from budget holders?

\section{VVI pacing for all?}

There are strong arguments against VVI for all. Dual chamber pacing provides better effort tolerance and general wellbeing. ${ }^{89}$ The pacemaker syndrome seen with VVI pacing $^{10}$ may cause important symptoms in $7-25 \%$ of patients ${ }^{11}$ and has been described in a subclinical form. ${ }^{12}$ Cardiologists with direct clinical experience recognise the distinct improvement in patients upgraded from VVI to rate adaptive pacing. The advantages of DDD over VVIR are less clear. ${ }^{13} 14$

The pacing population is generally an elderly one $(60 \% \text { are older than } 75)^{1}$ and no prospective comparative surveys have concentrated on this age group which includes infirm patients with multisystem disease and probably multiple sources of symptoms which may limit the clinical impact of rate adaptive pacing. Fit, active elderly patients must at least gain equal if not greater benefit from rate adaptive pacing than younger patients. Rate adaptation will provide improvements in cardiac output unobtainable with VVI pacing and significantly improve the quality of life; perhaps even being a crucial factor in allowing continued independence. The potential reduction in hospital attendance and drug treatment for heart failure or other morbidity is unknown, though it is implied in several reports and retrospective data suggested improved survival with DDD pacing in patients with congestive cardiac failure. ${ }^{15}$

\section{Problems with dual chamber pacing for all}

Dual chamber pacemakers are not without problems. More skill is needed to position an electrode in the atrium than in the ventricle. The technique can be readily learnt, however, and the availability of the floating atrial sensor for VDD pacing with a single electrode may make the technique easier. However, the floating sensors are unlikely to be as good as an atrial electrode. Currently VDD devices are expensive but when they cost less than a dual chamber system they may become attractive for use in the elderly population with complete heart block.

Because programming and follow up of rate adaptive pacemakers are more complex, patients need to return to the implanting centre for follow up (in our case a round trip of up to 150 miles). Rate responsive systems also require appropriate exercise testing to check correct programming and Doppler echocardiography may be needed to refine atrioventricular conduction times.

\section{More pacing centres}

The devolution of pacing practice to district general hospitals must be considered. This should be encouraged provided the benefits of a local service to patients are not accompanied by a reduction in quality. Pacing requires enthusiastic local staff both at consultant and technical level rather than a management led instruction to perform pacing in house at lower cost. One distinct benefit of the expansion of the service base will be to increase the overall numbers of patients paced and this may bring us into line with the rest of Europe and towards a target rate of 300-350 implants per million per year.

\section{The case for atrial pacing}

In sinus node disease, atrial pacing does offer reductions in atrial fibrillation, systemic emboli (especially stroke), heart failure, and possibly mortality. ${ }^{16} 17$ The increased age and degree of heart failure in the VVI patients unfortunately weakens these retrospective data but preliminary data on 225 patients in a prospective study firmly accord with a benefit. The later development of third degree atrioventricular block is often cited against AAI/AAIR pacing but the largest published review shows an incidence of just $0.6 \%$ a year with only $2 \%$ needing an upgrade to DDD. ${ }^{18}$ We favour AAI pacing in patients

Explanation of the pacing modes and list prices for the pulse generators

\begin{tabular}{|c|c|c|}
\hline Mode & Explanation & Cost \\
\hline VVI/AAI & $\begin{array}{l}\text { Fixed rate ventricular/atrial pacing } \\
\text { Inhibition of pacing with higher spontaneous rates }\end{array}$ & $£ 1350$ \\
\hline AAIR/VVIR & $\begin{array}{l}\text { Single chamber pacemakers with sensors } \\
\text { Pacing rate increases with exercise }\end{array}$ & $£ 2090$ \\
\hline DDD & $\begin{array}{l}\text { Dual chamber sensing and pacing } \\
\text { Atrial sensing or pacing with ventricular tracking }\end{array}$ & $£ 2300$ \\
\hline VDD & $\begin{array}{l}\text { Ventricular pacing, dual chamber sensing, no atrial pacing } \\
\text { Specialised electrode with "floating" atrial sensor }\end{array}$ & $£ 2300$ \\
\hline DDDR & $\begin{array}{l}\text { Rate responsive dual chamber pacing } \\
\text { If sinus rate responses are poor }\end{array}$ & $£ 3000$ \\
\hline
\end{tabular}


with normal atrioventricular intervals, normal interventricular conduction, and no Wenckebach atrioventricular block below $150 \mathrm{bpm}$. There is a need for rate smoothing with AAI pacing, and AAIR or DDDR pacing is now a well recognised requirement in patients with erratic sinus rates and chronotropic incompetence.

\section{New indications for pacing}

Indications for DDD pacing may increase. Evidence suggests that short atrioventricular delays are advantageous in patients with cardiomyopathy and heart failure and that this advantage may extend to those without conduction problems. ${ }^{19}$ Patients with hypertrophic cardiomyopathy have also been shown to benefit from short atrioventricular delays, possibly because they produce abnormal septal motion and so reduce the outflow tract obstruction. $^{20}$ Rigorous prospective studies will be needed to establish what benefits can be gained in these new areas. This could lead to an increase in the number of implants.

\section{What needs to be done}

The current climate of controversy in pacing seems to reflect a lack of uniformity in quality standards for pacing. While many patients are "well" with VVI pacing, it is likely that the elderly people who are paced are not as well treated as they should be: but to date we do not know how much better they could be treated. Many cardiologists seem to be satisfied by the prevention of syncope and sudden death, and too much of the responsibility for pacing seems to be devolved to junior staff. Others remain frustrated by budget constraints and reluctantly apply an agist policy to the selection of pacing mode. This may be because pressure on cardiologists prevents adequate participation at a senior level in pacing services.

In the younger ambulant patient the value of rate adaptive pacing is established and modern cardiac centres should provide this service. In addition enthusiasts must provide objective data to support the provision of rate adaptive pacing for the elderly and to characterise the patients who would most likely benefit. A properly structured prospective study to compare single and dual chamber pacing would provide accurate information upon which financial decisions could be made (How much benefit and are we prepared to buy that treatment?). This could offer the best support for the BPEG guidelines. Would such a study be ethical? How can it not be if the current clinical practice is so strongly inclined towards simple VVI pacing? We are planning such a prospective study in complete heart block which will be a multicentre initiative UK-PACE (United Kingdom Pacing And Cardiovascular Events). Interested centres will be invited to join.

The division will continue between the enthusiasts who have negotiated/committed more resources to pacing and those who provide a basic service. Perhaps if purchasers opt to "keep things cheaper" the changing purchaser profile (district health authorities and general practice fund holders) will influence progress in pacing and perhaps even reverse the current drift towards rate adaptive pacing. Cardiologists active in pacing must be alert to this and insist on maintaining and improving current standards of treatment.

We recommend the individual assessment of elderly patients who require pacing. In atrioventricular block those who are ambulant and in whom pacing will be virtually continuous are likely to benefit from rate adaptive pacing. We strongly favour DDD systems and believe that the atrial sensor is best. The decisions in sinus node disease are more complex but we support AAI pacing and recognise the need for sensor driven systems (AAIR or DDDR). We realise that with an aging population the NHS budget will be increasingly stretched and therefore it is necessary to justify our recommendations with organised prospective trials that will allow us to adopt a non-agist policy in the twenty first century and make the VVI mode one of historic interest.

GILLIAN E PAYNE

Groby Road Hospital,Groby Road, J DOUGLAS SKEHAN Leicester LE3 $9 Q E$

1 Report of a working party of the British Pacing and Electrophysiology Group. Recommendations for pacemaker prescription for symptomatic bradycardia. Br Heart $\mathcal{f}$ 1991;66:185-91.

2 Nathan AW, Davies DW. Is VVI pacing outmoded? Br Heart $f$ 1992; 67:285-8.

3 de Belder MA, Linker NJ, Jones S, Camm AJ, Ward DE. Cost implications of the British Pacing and Electrophysiology Groups recommendations of the British Pacing and $B M \mathcal{F}$ 1992;305:861-5.

4 Sutton R, Bourgeois I. The foundations of cardiac pacing: an illustrated practical guide to basic pacing. Mount Kisco, NY: Futura Publishing, 1991; vol 1, part 1:304-8.

5 Letters. BMF 1992;305:1431-2.

6 Ray SG, Griffith MJ, Jamieson S, Bexton RS, Gold RG. Impact of the recommendations of the British Pacing and Electrophysiology Group on pacemaker prescription and on the immediate costs of pacing in the Northern Region. Br Heart $\mathcal{F} 1992 ; 68: 531-4$

7 Petch MC. Who needs dual chamber pacing? BMf 1993;307:215-6.

8 Perrins EJ, Morley CA, Chan SL, Sutton R. Randomised controlled trial of physiological and ventricular pacing. Br Heart $\mathcal{F} 1983 ; 50: 112-7$.

9 Smedgard P, Kristensson B-E, Kruse I, Ryden L. Rate responsive pacing by means of activity sensing versus single rate ventricular pacing: A double blind crossover study. PACE 1987;10:902-15.

10 Ausubel K, Furman S. The pacemaker syndrome. Ann Intern Med 1985 103:420-9.

11 Barold SS, Mugica J, eds. The third decade of cardiac pacing: advances in technology and clinical applications. New York: Futura Publishing 1982:22-42.

12 Sulke N, Dritsas A, Bostock J, Wells A, Morris R, Sowton E. Subclinical pacemaker syndrome: a randomised study of symptom free patients with ventricular demand (VVI) pacemakers upgraded to dual chamber devices. Br Heart $\mathcal{F}$ 1992;67:57-65.

13 Oldroyd KG, Rae AP, Carter R, Wingate C, Cobbe SM. Double blind crossover comparison of the effects of dual chamber pacing (DDD) and ventricular rate adaptive (VVIR) pacing on neuroendocrine variables, exercise performance, and symptoms in complete heart block. Br Heart fx 1991;65:188-93.

14 Linde-Edelstam C, Hjemdahl P, Pehrsson SK, Astrom H, Norlander R Is DDD pacing superior to VVIR? A study on cardiac sympathetic nerve Is DDD pacing superior to VVIR? A study on cardiac sympathetic nerve activity and myocardial oxy $1992 ; 15: 425-34$.

15 Alpert MA, Curtis J, Sanfelippo JF, Flaker GC, Walls JT, Mukerii V, et al. Comparative survival after permanent ventricular and dual chamber pacing for patients with and without preexistent congestive cardiac heart failure. F Am Coll Cardiol 1986;7:925-32.

16 Rosenqvist M, Obel IW. Atrial pacing and the risk of AV block: is there time for a change in attitude? $P A C E$ 1989;12:97-101.

17 Rosenqvist $M$, Brandt J, Schuller $H$. Long term pacing in sinus node disease; effects of stimulation mode on cardiovascular morbidity and mortality. Am Heart $₹$ 1988;116:16-22.

18 Bianconi L, Boccadamo R, Di Florio A, et al. Atrial versus ventricular stimulation in sick sinus syndrome; effects on morbidity and mortality [abstr] PACE 1989;12:1236.

19 Brecker SJ, Xiao HB, Sparrow J, Gibson DG. Effects of dual-chamber pacing with short atrioventricular delay in dilated cardiomyopathy. Lancet 1992;340:1308-12.

20 Fananapazir LF, Cannon RO, Tripodi D, Panza JA. Impact of dualchamber permanent pacing in patients with obstructive hypertrophic cardiomyopathy. Circulation 1992;85:2149-61. 